\title{
Adhesion Strength of Wood Based Composites Coated with Cellulosic and Polyurethane Paints
}

\author{
Tuncer Dilik, ${ }^{1}$ Seda Erdinler, ${ }^{1}$ Ender Hazır, ${ }^{1}$ Hüseyin Koç, ${ }^{1}$ and Salim Hiziroglu ${ }^{2}$ \\ ${ }^{1}$ Department of Forest Industrial Engineering, Faculty of Forestry, Istanbul University, 34473 Istanbul, Turkey \\ ${ }^{2}$ Natural Resource Ecology and Management, Oklahoma State University, Stillwater, OK 74078-6013, USA \\ Correspondence should be addressed to Tuncer Dilik; tuncerd@istanbul.edu.tr and Salim Hiziroglu; salim.hiziroglu@okstate.edu
}

Received 1 April 2015; Revised 5 May 2015; Accepted 8 May 2015

Academic Editor: Dimitrios G. Aggelis

Copyright (C) 2015 Tuncer Dilik et al. This is an open access article distributed under the Creative Commons Attribution License, which permits unrestricted use, distribution, and reproduction in any medium, provided the original work is properly cited.

\begin{abstract}
The objective of this study was to determine adhesive strength of particleboard and medium density fiberboard (MDF) finished with two types of paints. Samples were coated using cellulosic and polyurethane based paints. Adhesion strength and coating layer thickness of each sample were measured using pull-off testing method and PosiTector equipment, respectively. The highest adhesion strength value of 3.62 MPa was found for MDF samples coated with paint. Based on the statistical analysis type of substrate significantly influenced overall adhesion strength of the samples while type and layer thickness of paint as well as number of layers applied to the surface of specimens have not affected significantly adhesion resistance of the panels used in this work. It appears that pull-off test can effectively be used to determine and evaluate adhesion strength of the samples considered in the experiments.
\end{abstract}

\section{Introduction}

Wood composites such as particleboard and fiberboard, primarily medium density fiberboard (MDF), are prime products as substrate for thin overlays and direct finishing to be used in furniture and cabinet production. Their surface quality and type of the finishing material are two important parameters influencing overall quality of the final product. It is a well-known fact that hygroscopic characteristic of wood composite panels plays an important role in development of a good bonding between substrate and coating in a typical finishing process.

Although there are several major methods to enhance stability and appearance of wood composites finishing of such panels using varnishes, stains, and painting is still considered as the most popular one among the others. It is a fact that coating the surface of wood composites with different types of finishes will not only improve its appearance but also extend its service life. Unless there is a sufficient amount of adhesive strength of coating on the surface, service life of the finishing will not be very long and would result in a deterioration. Therefore it is important to evaluate such adhesive strength on the panels employing several techniques such as tape peeling, observing the cross cut, and pull-off test. The last one was effectively employed to evaluate adhesion strength of wood samples coated with different finishes in previous studies [1-7]. The adhesion strength of stained, bleached, and preservatively treated wood specimens from pine, chestnut, and beech was evaluated in a past study [5]. It was found that bleaching had an adverse influence on adhesion strength of coated samples while stained samples had an average adhesion strength of $1.58 \mathrm{~N} / \mathrm{mm}^{2}$ [5]. In any kind of surface treatment of wood and wood based products, adhesion resistance is one of the major factors influencing the overall finishing quality and its effective service life. The finishing type and surface properties of the material where the surface treatment is applied as well as the number of layers used and layer thickness can also be considered as main parameters for a good finishing of the panels. Although there are various national and international standards of surface treatments in the form of finishing and their characteristics, evaluation of the coating characteristics including adherence between two members still remains at subjective perspective [8-10]. Therefore, in the majority of the applications, the surface treatments would cause an increase in the production costs and prevent achieving the desired surface performance 
values due to lack of detailed information in this area [1113]. As mentioned above although various methods have been developed to determine adhesion strength of wood composites pull-off test still keeps its popularity due to its practicality and precision. Adhesion mechanisms between the wood and wood composite panels and protective layers have been examined in several past studies [14-18]. Oak samples were coated with polyurethane base varnish which was investigated as a function of moisture content in previous study [19]. Various works have also been carried out to determine surface roughness of wood samples in relation to adhesion strength coated wood samples with different types of finishes [20].

Richter et al. concluded that rougher surface characteristics of radial and tangential grain orientations of three different hardwood species required higher amount of finishing material and overall quality of finishing was influenced by the surface roughness of the substrate [20]. In general it is expected that rougher surface of the substrate results in better bonding ability of peak and valley points of the surface. Therefore a typical particleboard would result in better adhesion strength than that of MDF. Also subjective numerical information on the surface quality of the wood composites would provide valuable information so that not only can amount of finishing chemical be controlled but also final product can be manufactured with a better quality. There are numerous studies carried out on surface quality specifically surface roughness and overlaying characteristics of both commercially and laboratory produced particleboard and MDF [7-9, 20]. However there is very little or no information on how cellulose and polyurethane based finishing materials would adhere to wood composite substrates as a function of coating thickness and panel type. Therefore it was the objective of this experimental study to evaluate adhesion strength of the particleboard and MDF coated with two types of paints. Such finished panel products can be used with a better efficiency in the form of higher quality value-added products $[5,9]$.

\section{Materials and Methods}

Commercially manufactured particleboard and MDF panels were supplied by a local manufacturer. A total of 36 samples were cut into $1000 \mathrm{~mm}$ by $200 \mathrm{~mm}$ size having a thickness of $18 \mathrm{~mm}$. Density levels of particleboard and MDF samples were measured using randomly cut specimens with $50 \mathrm{~mm}$ by $50 \mathrm{~mm}$ squares. Each sample was weighed and its dimensions were measured at an accuracy level of $0.1 \mathrm{~g}$ and $0.01 \mathrm{~mm}$, respectively. Average density of particleboard was determined as $0.56 \mathrm{~g} / \mathrm{cm}^{3}$ while this value was $0.68 \mathrm{~g} / \mathrm{cm}^{3}$ for MDF samples. Table 1 displays specifications of commercially manufactured interior solvent-based cellulosic and polyurethane paints used as finishing materials. Samples were conditioned in a climate room having a temperature of $20^{\circ} \mathrm{C}$ and relative humidity of $65 \%$ until they reach a moisture content of $10 \%$ before they were coated with two types of finishes. Samples were coated employing a spray gun using a pressure of $0.80 \mathrm{MPa}$ at a spread rate of $120 \mathrm{~g} / \mathrm{m}^{2}$.
TABLE 1: Specifications of the finishing materials used for the experiments.

\begin{tabular}{lccc}
\hline Paint type & $\begin{array}{c}\text { Density } \\
\left(\mathrm{g} / \mathrm{cm}^{3}\right)\end{array}$ & $\begin{array}{c}\text { Solid } \\
\text { content (\%) }\end{array}$ & $\begin{array}{c}\text { Viscosity } \\
(\mathrm{DIN6} \text {. sn })\end{array}$ \\
\hline $\begin{array}{l}\text { Cellulosic base } \\
\quad \text { Primer coating }\end{array}$ & 1.30 & 58 & 60 \\
$\quad \begin{array}{l}\text { Top coat } \\
\text { Polyurethane base }\end{array}$ & 0.98 & 44 & 130 \\
$\quad$ Primer coating & 1.42 & 77 & 115 \\
$\quad$ Top coat & 1.18 & 50 & 290 \\
\hline
\end{tabular}

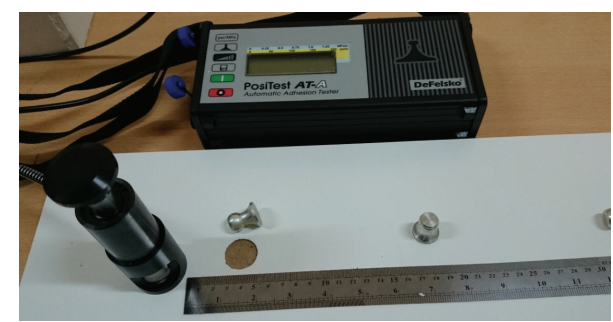

FIGURE 1: Adhesion resistance test setup used for the experiments.

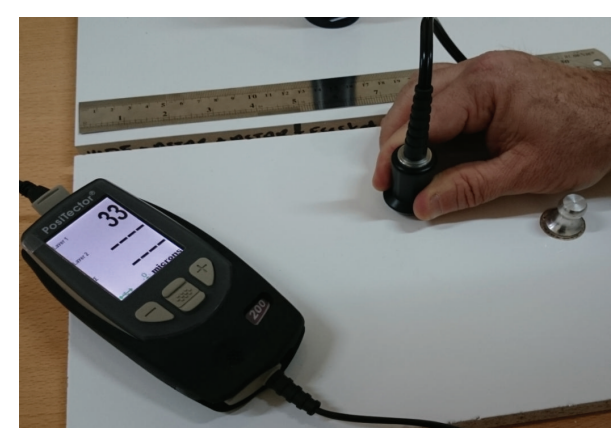

FIGURE 2: Coating thickness measurement equipment.

Sequential application of primer and top coat of the finishes was applied to the surface of each of the panels with an angle of 90 degrees. After each application the layer thicknesses of the coats were measured with PosiTector Probe 200. In the next step samples were conditioned for a week before adhesion strength tests were carried out using PosiTest ATA Automatic Adhesion Tester based on ASTM D 4541, EN ISO 4624 standards [13, 21-23]. Table 2 displays sampling schedule. Minitab 16 software program and multiple variance analysis "ANOVA" test have been used for the statistical assessments of the results. The data was considered at the level of $\alpha=0.05$ for determining the effect and significance levels of the factors examined. For the cases where the factor effects were significant with an error margin (Table 5), dual comparisons have been performed employing Tukey's test [14]. Figures 1 and 2 illustrate adhesion tester equipment and layer thickness measuring setup, respectively. 
TABLE 2: Sampling schedule.

\begin{tabular}{|c|c|c|c|}
\hline Panel type & Finish type & $\begin{array}{c}\text { Number } \\
\text { of samples }\end{array}$ & Finishing process \\
\hline \multirow{6}{*}{$\mathrm{MDF}$} & \multirow{3}{*}{ Cellulosic paint } & 3 & Application 1 (primer + primer + top coat) \\
\hline & & 3 & Application 2 (primer + primer + top coat + top coat $)$ \\
\hline & & 3 & Application 3 (primer + primer + top coat + top coat + top coat $)$ \\
\hline & \multirow{3}{*}{ Polyurethane paint } & 3 & Application 1 (primer + primer + top coat $)$ \\
\hline & & 3 & Application $2($ primer + primer + top coat + top coat $)$ \\
\hline & & 3 & Application 3 (primer + primer + top coat + top coat + top coat $)$ \\
\hline \multirow{6}{*}{ Particleboard } & \multirow{3}{*}{ Cellulosic paint } & 3 & Application $1($ primer + primer + top coat $)$ \\
\hline & & 3 & Application $2($ primer + primer + top coat + top coat $)$ \\
\hline & & 3 & Application 3 (primer + primer + top coat + top coat + top coat $)$ \\
\hline & \multirow{3}{*}{ Polyurethane paint } & 3 & Application $1($ primer + primer + top coat $)$ \\
\hline & & 3 & Application $2($ primer + primer + top coat + top coat $)$ \\
\hline & & 3 & Application 3 (primer + primer + top coat + top coat + top coat $)$ \\
\hline
\end{tabular}

TABLE 3: Average coating thickness and adhesion strength values of the samples.

\begin{tabular}{|c|c|c|c|c|}
\hline Panel type & Finish type & Application type & Average coating thickness $(\mu)$ & Average adhesion strength (MPa) \\
\hline \multirow{6}{*}{$\mathrm{MDF}$} & \multirow{3}{*}{ Cellulosic base } & 1 & $179(5.57)$ & $3.62(0.36)$ \\
\hline & & 2 & $181(11.68)$ & $2.86(0.15)$ \\
\hline & & 3 & $236(5.51)$ & $2.78(0.19)$ \\
\hline & \multirow{3}{*}{ Polyurethane base } & 1 & $167(2.08)$ & $2.95(0.31)$ \\
\hline & & 2 & $239(13.32)$ & $2.37(0.11)$ \\
\hline & & 3 & $345(8.33)$ & $3.58(0.21)$ \\
\hline \multirow{6}{*}{ Particleboard } & \multirow{3}{*}{ Cellulosic base } & 1 & 249 (13.89) & $0.83(0.04)$ \\
\hline & & 2 & $322(19.08)$ & $1.54(0.07)$ \\
\hline & & 3 & $334(6.81)$ & $0.96(0.13)$ \\
\hline & \multirow{3}{*}{ Polyurethane base } & 1 & $199(10.54)$ & $0.85(0.10)$ \\
\hline & & 2 & $295(3.06)$ & $1.16(0.09)$ \\
\hline & & 3 & $363(9.02)$ & $0.97(0.21)$ \\
\hline
\end{tabular}

(Numbers in parenthesis are standard deviations values.)

\section{Results and Discussion}

Table 3 displays average adhesion strength and coating thickness of the samples finished with cellulosic and polyurethane based paints. The highest adhesion strength value of 3.62 (0.36) MPa was determined for MDF samples finished with application of cellulosic paint having two primers and one top coat. Particleboard specimens finished with the same type of paint having two primers and three top coats had the lowest adhesion strength value of $0.97(0.21) \mathrm{MPa}$. Overall particleboard samples resulted in lower adhesion strength values in all applications as well as using two types of paint than those of MDF specimens as can be observed in Table 3. Statistically significant differences were found between adhesion values of two different panels products in all cases. In a previous study adhesion strength of MDF samples coated with polyurethane varnished before and after exposure to $85 \%$ relative humidity level resulted in similar values to those found in this work [7]. Once MDF samples were exposed to high humidity their surface quality became rougher and acted as a kind of barrier between coat and substrate reducing their adhesion strength characteristics $[7,24]$. Although in this study no humidity exposure of the samples was used particleboard samples having relatively rougher surfaces as compared to that of MDF had lower interaction between the substrate and coatings without regarding any kind of finishing application processes employed in the experiments. Consequently such samples resulted in lower adhesion strength values. In both types of finishes statistical analysis also revealed that there was no significant effect of paint type and application process along the coating thickness on adhesion strength values of the specimens as can be seen in Table 4. It is clear that thickness of the finishes increased with increasing number of coats. For example, average finishing thickness of MDF specimens coated using application number 1 was 173 microns while corresponding value of finish in the case of particleboard samples was 224 microns. Higher thickness of finish in the case of particleboard samples can again be related to their rougher surface quality acting as a barrier to development of densified smooth coating on the substrate. As number of coatings increased similar trends were also determined in both types of finishing materials. Figure 3 also shows weak 
TABLE 4: The analysis of variance for adhesion strength of the samples.

\begin{tabular}{|c|c|c|c|c|c|}
\hline Source & DF & SS & MS & $F$ value & $P$ value \\
\hline Panel type & 1 & 35.3628 & 35.3628 & 370.84 & 0.000 \\
\hline Finishing type & 1 & 0.1369 & 0.1369 & 1.44 & 0.242 \\
\hline Application type & 2 & 0.0624 & 0.0312 & 0.33 & 0.724 \\
\hline Panel type $*$ paint type & 1 & 0.0009 & 0.0009 & 0.01 & 0.923 \\
\hline Panel type $*$ application type & 2 & 2.3954 & 1.1977 & 12.56 & 0.000 \\
\hline Finishing type $*$ application type & 2 & 1.2465 & 0.6232 & 6.54 & 0.005 \\
\hline Error & 26 & 2.4793 & 0.0954 & & \\
\hline Lack-of-fit & 2 & 0.8701 & 0.4350 & 6.49 & 0.006 \\
\hline Pure error & 24 & 1.6093 & 0.0671 & & \\
\hline Total & 35 & 41.6842 & & & \\
\hline
\end{tabular}

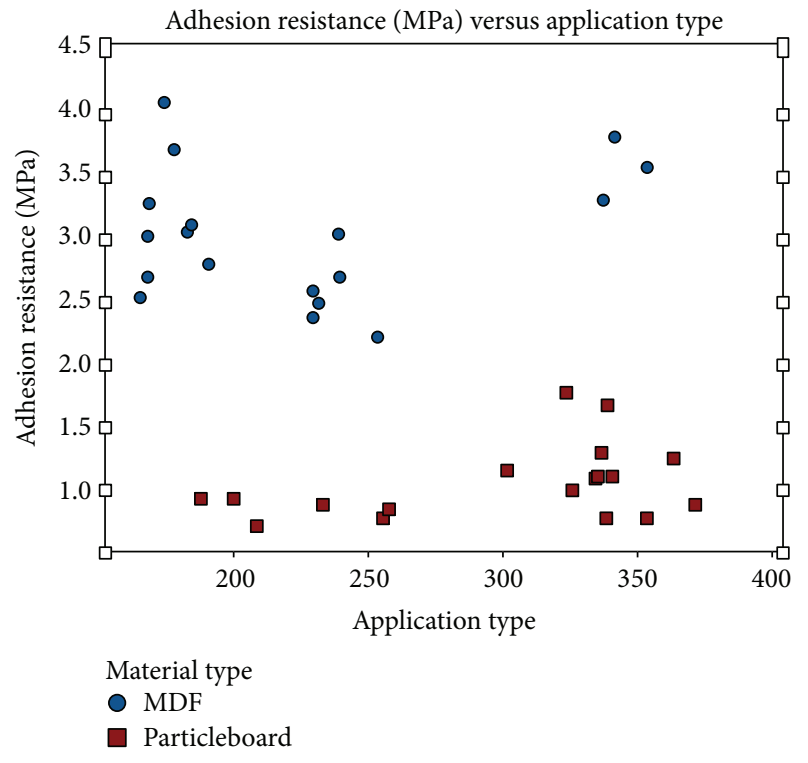

FIGURE 3: Relationship between layer thickness and adhesion resistance of two types of panels.

TABLE 5: Grouping analysis based on Tukey's test of adhesion resistance of the samples as a function of types of panel, paints, and applications.

\begin{tabular}{lccc}
\hline & $N$ & Mean & Grouping \\
\hline $\begin{array}{l}\text { Panel type } \\
\text { MDF }\end{array}$ & 18 & 3.033 & $\mathrm{~A}$ \\
$\quad$ Particleboard & 18 & 1.051 & $\mathrm{~B}$ \\
$\begin{array}{l}\text { Paint type } \\
\text { Cellulosic }\end{array}$ & 18 & 2.103 & \\
$\quad$ Polyurethane & 18 & 1.980 & $\mathrm{~A}$ \\
Application type & & & $\mathrm{A}$ \\
1 & 12 & 2.071 & \\
2 & 12 & 1.983 & $\mathrm{~A}$ \\
3 & 12 & 2.071 & $\mathrm{~A}$ \\
\end{tabular}

relationship between adhesion strength and layer thickness of the coats.
In the study, the material type, paint type, and application type, the factors whose effects on the adhesion resistance are examined, are evaluated by applying multiple variance analysis (ANOVA). In this analysis, the variable model explanation level is found as $94 \%$ (R-sq). The effect factors examined are evaluated separately with and without interaction.

\section{Conclusions}

Adhesion strength of MDF and particleboard coated with interior type of cellulosic and polyurethane finishes was tested in this work. Having densified and smooth surface of MDF specimens resulted in enhanced adhesion strength characteristics between finishing materials and substrate as compared to that of particleboard samples. In most cases lower average coating thickness resulted in relatively acceptable adhesion strength values in both particleboard and MDF samples. None of the failures took place in the fibers or particles on the panels. Preliminary data from this work would help to determine optimum amount of adhesion as a function of finish layer thickness for an effective finishing process to reduce overall production cost. In further studies determination of adhesion strength of such samples exposed to different relative humidity levels would give a better understanding of finished panel products during their service life under environmental conditions.

\section{Conflict of Interests}

The authors declare that there is no conflict of interests.

\section{Acknowledgment}

This study is supported by the Scientific Research Projects Coordination Unit of Istanbul University with Project no. UDP-42282.

\section{References}

[1] T. Dilik, H. Koç, E. Hazir, and E. S. Erdinler, "Surface treatment, layer thickness and surface performance relations of wood materials," in Proceedings of the 57th International Convention of 
Society of Wood Science and Technology, pp. 568-573, Technical University in Zvolen, Zvolen, Slovakia, June 2014.

[2] A. Kurtoglu, Wood Material Surface Treatments, General Information, Volume 1, Faculty of Forestry Publication no: 463, Istanbul University, Istanbul, Turkey, 2000.

[3] A. S. Şenok, "Some considerations related to pain industry in Turkey," ISO Journal, p. 32, 2000.

[4] A. Sönmez, Surface Layer Treatments in Wood Works I: Preparation and Coloring, Gazi University, Faculty of Technical Education, Ankara, Turkey, 2000.

[5] M. Budakçı and A. Sönmez, "Determining the adhesion resistance of some wood varnishes on different wood material surfaces," Journal of the Faculty of Engineering and Architecture of Gazi University, vol. 25, no. 1, pp. 111-118, 2010.

[6] N. Çakıcıer, Changes determined by aging on wood material surface treatment layers [Ph.D. thesis], Istanbul University, Institute of Science, Istanbul, Turkey, 2007.

[7] T. Özdemir and S. Hiziroglu, "Evaluation of surface quality and adhesion strength of treated solid wood," Journal of Materials Processing Technology, vol. 186, no. 1-3, pp. 311-314, 2007.

[8] E. Hazir, A modeling work on evaluating the quality of wooden surface quality [M.S. thesis], Istanbul University, Institute of Science, Istanbul, Turkey, 2012.

[9] P. Ahola, "Adhesion between paint and wood substrate," Surface Coatings International, vol. 74, no. 5, pp. 173-176, 1991.

[10] M. Nejad and P. Cooper, "Exterior wood coatings. Part-2: modeling correlation between coating properties and their weathering performance," Journal of Coatings Technology Research, vol. 8, no. 4, pp. 459-467, 2011.

[11] K. L. Mittal, Commentary, Adhesion Measurement of Films and Coatings, VSP, Utrecht, The Netherlands, 1995.

[12] M. Jaic and R. Zivanovic, "The influence of the ratio of the polyurethane coating components on the quality of finished wood surface," Holz als Roh- und Werkstoff, vol. 55, no. 5, pp. 319-322, 1997.

[13] G. L. Nelson, Adhesion, Paint and Coating Testing Manuel, chapter 44, ASTM Special Technical Publication, Philadelphia, Pa, USA, 1995.

[14] K. Özdemir, Statistical Data Analysis with Package Programs, vol. 2, Nisan Kitapevi, Ankara, Turkey, 9th edition, 2013.

[15] A. P. Singh, B. Park, A. Nuryawan, and M. Kazayawoko, "Advances in probing wood-coating interface by microscopy: a review," Journal of Surface Engineered Materials and Advanced Technology, vol. 03, no. 01, pp. 49-54, 2013.

[16] R. S. Williams, J. E. Winandy, and W. C. Feist, "Paint adhesion to weathered wood," Journal of Coatings Technology, vol. 59, no. 749 , pp. 43-49, 1987, http://www.fpl.fs.fed.us/documnts/ pdf1987/willi87a.pdf.

[17] R. S. Williams, P. L. Plantinga, and W. C. Feist, "Photodegredation of wood affects paint adhesion," Forest Products Journal, vol. 40, no. 1, pp. 45-49, 1990.

[18] J. Kúdela and E. Liptáková, "Adhesion of coating materials to wood," Journal of Adhesion Science and Technology, vol. 20, no. 8, pp. 875-895, 2006.

[19] M. de Meijer and H. Militz, "Wet adhesion of low-VOC coatings on wood: a quantitative analysis," Progress in Organic Coatings, vol. 38, no. 3, pp. 223-240, 2000.

[20] K. Richter, W. C. Feist, and M. T. Knaebe, "The effect of surface roughness on the performance of finishes. Part 1. Roughness characterization and stain performance," Forest Products Journal, vol. 45, no. 7-8, pp. 91-97, 1995.
[21] ASTM, "Standard test method for pull-off strength of coatings using portable adhesion testers," ASTM D 4541, American Society for Testing and Materials, 1995.

[22] Turkish Standards Institution, TS EN ISO 4624, Paints and Varnishes-Pull-Off Test for Adhesion, Turkish Standards Institution, Ankara, Turkey, 2006.

[23] TSE, "Wooden furniture surfaces-determining the adhesion resistance of paint and varnish layers," TS 6884, Turkish Standards Institution, Ankara, Turkey, 2005.

[24] S. L. Bardage and J. Bjurman, "Adhesion of waterborne paints to wood," Journal of Coatings Technology, vol. 70, no. 878, pp. 39-47, 1998. 

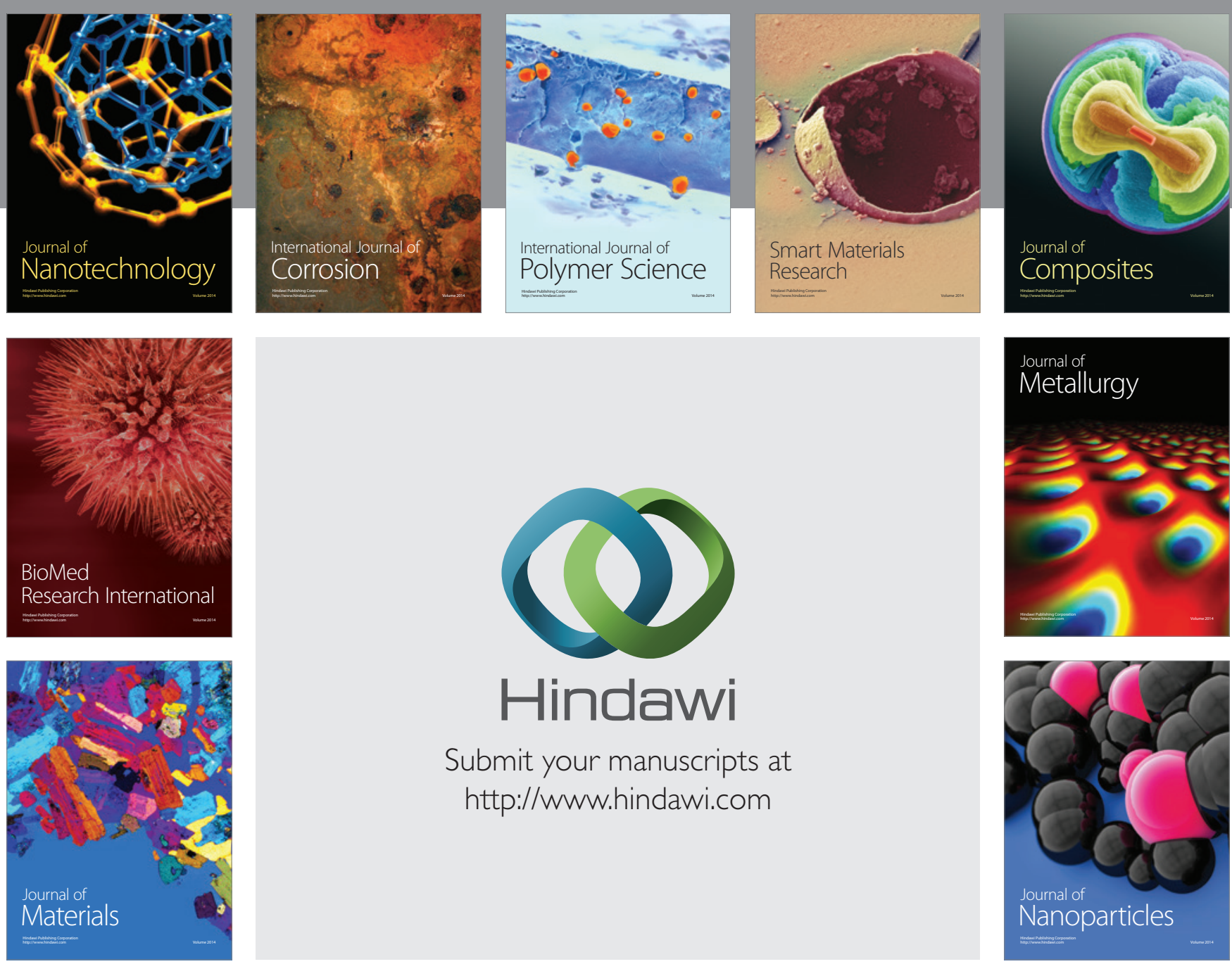

Submit your manuscripts at http://www.hindawi.com
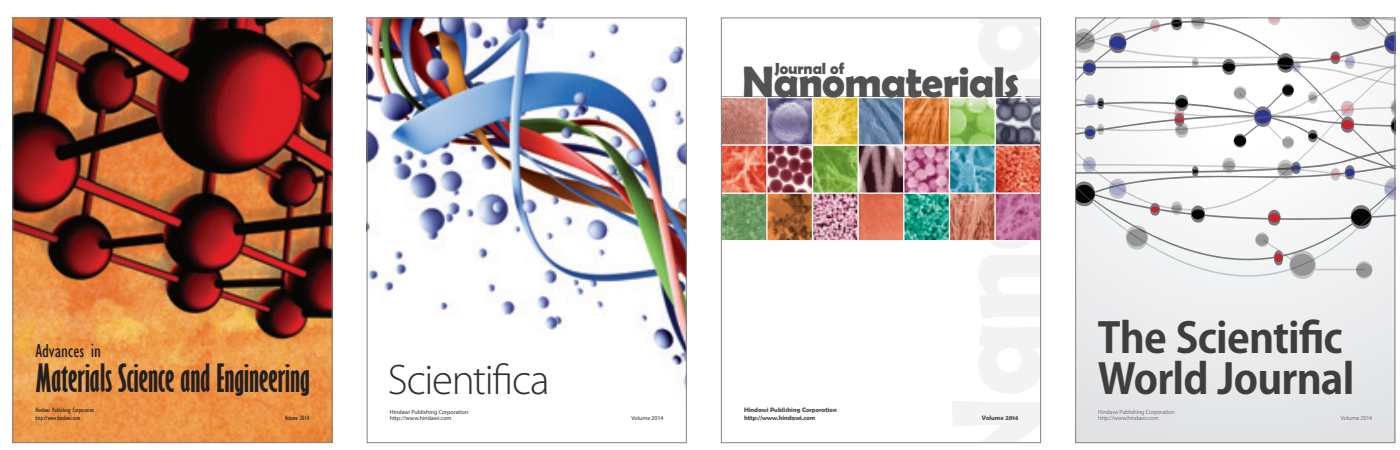

\section{The Scientific World Journal}
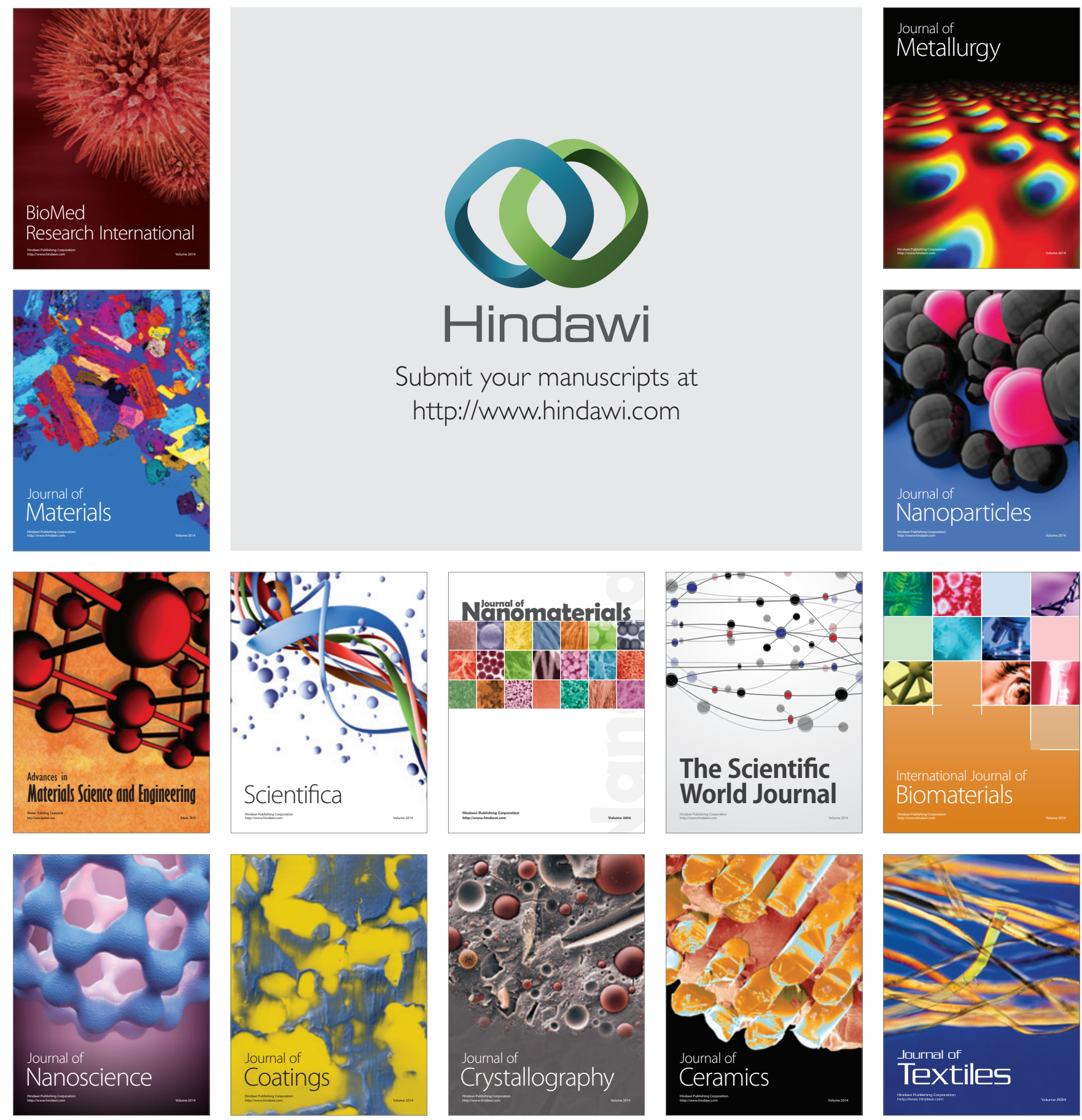